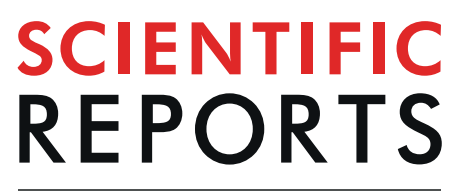

\title{
Phosphate Adsorption by Silver Nanoparticles-Loaded Activated Carbon derived from Tea Residue
}

\author{
Van Tuyen Trinh ${ }^{1}$, Thi Minh Phuong Nguyen ${ }^{2}$, Huu Tap Van ${ }^{3}$, Le Phuong Hoang ${ }^{4}$, \\ Tien Vinh Nguyen ${ }^{5}$, L. T. Ha ${ }^{6}$, Xuan Hoa Vu ${ }^{6}$, T. T. Pham ${ }^{7}$, Thi Nu Nguyen ${ }^{8}$, N. V. Quang ${ }^{9} \&$ \\ X.C. Nguyen ${ }^{10,11^{*}}$
}

This study presents the removal of phosphate from aqueous solution using a new silver nanoparticlesloaded tea activated carbon (AgNPs-TAC) material. In order to reduce costs, the tea activated carbon was produced from tea residue. Batch adsorption experiments were conducted to evaluate the effects of impregnation ratio of AgNPs and TAC, pH solution, contact time, initial phosphate concentration and dose of AgNPs-AC on removing phosphate from aqueous solution. Results show that the best conditions for phosphate adsorption occurred at the impregnation ratio AgNPs/TAC of $3 \% \mathrm{w} / \mathrm{w}, \mathrm{pH}$ 3 , and contact time lasting $150 \mathrm{~min}$. The maximum adsorption capacity of phosphate on AgNPs-TAC determined by the Langmuir model was $13.62 \mathrm{mg} / \mathrm{g}$ at an initial phosphate concentration of $30 \mathrm{mg} / \mathrm{L}$. The adsorption isotherm of phosphate on AgNPs-TAC fits well with both the Langmuir and Sips models. The adsorption kinetics data were also described well by the pseudo-first-order and pseudo-secondorder models with high correlation coefficients of 0.978 and 0.966 , respectively. The adsorption process was controlled by chemisorption through complexes and ligand exchange mechanisms. This study suggests that AgNPs-TAC is a promising, low cost adsorbent for phosphate removal from aqueous solution.

Phosphate is the important nutrient in the Earth's natural ecosystem. However, large amounts of phosphate in wastewater discharged into the environment are the main reason for eutrophication in aquatic environments, resulting in serious pollution and economic problems ${ }^{1}$. The source of phosphate pollution usually originates from a wide range of human activities such as agricultural runoff, domestic wastewater, and industrial discharge ${ }^{2}$. The discharge of phosphate into aqueous ecosystems has increased in recent decades due to human activities such as industrialization. For this reason it is vital to remove phosphate from wastewater before discharging it into aquatic ecosystems. In surface water, the primary dissolved form of phosphorus is ortho phosphorus. Particulate phosphorus can exist in various forms depended on the environmental conditions. Forms of organic compounds of particulate phosphorus include algae, plant and animal tissue, waste solids, etc. The form of organic particulate phosphorus can be decomposed by microorganisms and dissolved to phosphate. Organic phosphates can enter the environment through insecticides that inhibit acetyl cholinesterase in neuromuscular systems ${ }^{3}$. Nutrient adsorption and allocation may be affected by sublethal concentrations of inorganic and organic phosphates. Therefore, growth of marine invertebrates is also decreased ${ }^{4}$.

${ }^{1}$ Institute of Environmental Technology, Vietnam Academy of Science and Technology, 18 Hoang Quoc Viet road, Ha Noi city, Vietnam. ${ }^{2}$ Faculty of Environment and Chemical Engineering, Duy Tan University (DTU), 254 Nguyen Van Linh road, Da Nang, Vietnam. ${ }^{3}$ Faculty of Natural Resources and Environment, TNU-University of Sciences (TNUS), Tan Thinh Ward, Thai Nguyen City, Vietnam. ${ }^{4}$ Faculty of Civil and Environmental Engineering, Thai Nguyen University of Technology (TNUT), Tich Luong Ward, Thai Nguyen City, Vietnam. ${ }^{5}$ Faculty of Engineering and IT, University of Technology Sydney (UTS), Box 123, Broadway, Sydney, PO, Australia. ${ }^{6}$ Faculty of Physics and Technology, TNUUniversity of Sciences (TNUS), Tan Thinh Ward, Thai Nguyen City, Vietnam. ${ }^{7}$ Institute of Research and Development, Duy Tan University, Da Nang, 550000, Vietnam. ${ }^{8}$ Cao Bang Teacher's Training College, De Tham road, Cao Bang town, Cao Bang Province, Vietnam. ${ }^{9}$ Faculty of Chemistry, Ha Noi Pedagogical University 2, Vinh Phuc, Vietnam. ${ }^{10}$ Laboratory of Advanced Materials Chemistry, Advanced Institute of Materials Science, Ton Duc Thang University, Ho Chi Minh City, Vietnam. ${ }^{11}$ Faculty of Applied Sciences, Ton Duc Thang University, Ho Chi Minh City, Vietnam. *email: nguyenxuanca@tdtu.edu.vn 
Up till now, a number of treatment techniques including ion-exchange, biological treatment, physicochemical precipitation, membrane process, constructed wetland and adsorption methods have been used to treat phosphate contaminated wastewater ${ }^{5,6}$. Of these techniques, adsorption is a very promising method because of its simple operation, high efficiency and less likelihood of causing secondary pollution ${ }^{7}$. Several different adsorbents have been studied for phosphate adsorption from aqueous solution such as oxides and hydroxides ${ }^{8}$, fly ash ${ }^{9}$, clay minerals ${ }^{10}$, activated carbon ${ }^{11}$, and biochar ${ }^{12}$. Recently, nanomaterials have attracted significant scientific interest because of their exceptionally high surface area and high phosphate removal ability. In comparison to other materials, nanomaterials are very efficient in adsorbing contaminants in water ${ }^{13}$. In these nanomaterials, silver nanoparticles (AgNPs) have been investigated for their ability to remove pollutants in water such as cadmium ${ }^{14}$ and rhodamine $\mathrm{B}^{15}$. However, the application of silver nanoparticles in removing pollutants is still limited due to the high production costs.

Some researchers have loaded silver nanoparticles onto activated carbon to produce a new, inexpensive adsorbent for the removal of pollutants such as methylene blue ${ }^{16}$, malachite green ${ }^{17}$, and direct yellow $12^{18}$. These silver nanoparticles-loaded activated carbons revealed the high adsorption capacity compared with pristine activated carbon. However, to the best of our knowledge, studies on combining silver nanoparticles and activated carbon to make a new modified adsorbent for removing phosphate from aqueous solution are quite scarce. Consequently, this study develops a new adsorbent by directly loading silver nanoparticles onto activated carbon derived from tea residue (AgNPs-TAC) to remove phosphate from aqueous solution. The physico-chemical properties as well as adsorption mechanisms of phosphate on AgNPs-TAC were investigated through detailed material characterization and batch experimental results. Here, the effects of impregnation ratio (w/w) of tea activated carbon and AgNPs, $\mathrm{pH}$ solution, adsorption time, adsorbent dosage and initial concentrations of phosphate on adsorption capacity were investigated.

\section{Materials and Methods}

Materials. All chemicals, including $\mathrm{KH}_{2} \mathrm{PO}_{4}, \mathrm{AgNO}_{3}, \mathrm{NaOH}$, and $\mathrm{H}_{2} \mathrm{SO}_{4}$ were purchased from Merck (Darmstadt, Germany). Tea residue used for activated carbon production was collected from discarded branches and leaves of tea at the Tan Cuong tea garden in Thai Nguyen City, Vietnam.

Synthesis of silver nanoparticles. Silver nitrate $\left(\mathrm{AgNO}_{3}\right)$ was used as the precursor to create silver nanoparticles. Silver nanoparticles (AgNPs) were prepared utilizing the hydrothermal method as described by Nguyen et al. ${ }^{19}$. Firstly, $100 \mathrm{~mL}$ of $\mathrm{AgNO}_{3}$ solution $(0.001 \mathrm{M})$ was mixed with $0.2 \mathrm{~g}$ of starch to generate starch solutions containing $\mathrm{Ag}^{+}$ions. Then the solution was stirred vigorously with a magnetic stirrer at $70{ }^{\circ} \mathrm{C}$ to ensure the mixture retained its homogeneous nature. The temperature of the solution was continuously maintained at $70^{\circ} \mathrm{C}$ and $25 \mathrm{~mL}$ of sodium borohydrides $(0.001 \mathrm{M})$ was gradually added (drop by drop) into the mixture. Finally, the resultant solution was cooled to room temperature for further usage.

Preparation of the AgNPs-loaded tea activated carbon (AgNPs-TAC). The tea residue was firstly washed three times with tap water, three times with distilled water and then dried in an oven at $100{ }^{\circ} \mathrm{C}$ for $24 \mathrm{~h}$. The dried tea residue was then crushed and sieved to a size range from 1 to $2 \mathrm{~cm}$. The ground tea residue was heated under slow pyrolysis at $400^{\circ} \mathrm{C}$ for $2 \mathrm{~h}$ in a furnace (Nabertherm, model L3/11/B170, Germany) before being ground and sieved again to obtain a particle size of less than $0.5 \mathrm{~mm}$. The new tea activated carbon (TAC) was washed, dried at $105^{\circ} \mathrm{C}$ for $2 \mathrm{~h}$ and kept in a sealed bag before further study.

The incipient wet-impregnation technique was used to load AgNPs onto TAC as similarly described by Nguyen et al. ${ }^{19}$. The mixture of TAC and AgNPs was prepared by mixing AgNPs with TAC at various mass ratios, from $1.0-9.0 \% \mathrm{w} / \mathrm{w}$ in $250 \mathrm{~mL}$ Erlenmeyer flasks. The flasks were then shaken at $120 \mathrm{rpm}$ for $24 \mathrm{~h}$ in the dark. After impregnation, the wet particles were filtered and dried for $2 \mathrm{~h}$ at $105^{\circ} \mathrm{C}$ to obtain modified TAC (AgNPs-TAC). The AgNPs-TAC with an average particle size of less than $0.5 \mathrm{~mm}$ was used in the batch-mode adsorption experiments to remove phosphate from aqueous solution.

Batch adsorption experiments. Initially, an adsorption experiment was conducted to identify the optimal impregnation ratio of AgNPs and $\mathrm{TAC}^{16,19}$. Here, $0.03 \mathrm{~g}$ of AgNPs-TAC produced from four impregnation ratios of $1 \%, 3 \%, 6 \%$, and $9 \%$ was added into $50 \mathrm{~mL}$ Erlenmeyer flasks containing $25 \mathrm{~mL}$ solution of $30 \mathrm{mg} \mathrm{PO}_{4}{ }^{3-} / \mathrm{L}$. The flasks were sealed and shaken at $120 \mathrm{rpm}$ by a shaking machine (PH-2A, China) at the room temperature of $25 \pm$ $2{ }^{\circ} \mathrm{C}$. The liquid samples were filtered through $11 \mu \mathrm{m}$ filters before analysing them for phosphate residual concentration. Experimental results (presented in section 3.1) show that the impregnation ratio of 3\% was the best one. Thus, the AgNPs-TAC produced at this ratio was selected for detailed batch studies and material characterization.

Detailed batch experiments were conducted to evaluate the effects of various parameters ${ }^{16,19,20}(\mathrm{pH}$, initial phosphate concentration, contact time, and adsorbent dose) on the adsorption capacity of AgNPs-TAC for phosphate. Briefly, predetermined amounts of AgNPs-TAC were added into the $50 \mathrm{~mL}$ Erlenmeyer flasks containing $25 \mathrm{~mL}$ of $\mathrm{K}_{2} \mathrm{HPO}_{4}$ solution. The flasks were then shaken at $120 \mathrm{rpm}$ by a shaking machine ( $\mathrm{PH}-2 \mathrm{~A}$, China) at room temperature in the laboratory.

The effect of solution $\mathrm{pH}$ was carried out with a phosphate solution of $30 \mathrm{mg} / \mathrm{L}$ and AgNPs-TAC dose of $1.2 \mathrm{~g} / \mathrm{L}$ solution. Here, the $\mathrm{pH}$ of the solution was adjusted from 3 to 10 by adding either $\mathrm{H}_{2} \mathrm{SO}_{4} 0.1 \mathrm{M}$ or $\mathrm{NaOH} 0.1 \mathrm{M}$. Studies on the effect of contact time and adsorption kinetics were conducted at different time intervals, ranging from $5 \mathrm{~min}$ to $240 \mathrm{~min}$ at the initial phosphate concentration of $30 \mathrm{mg} / \mathrm{L}$, adsorbent dose of $1.2 \mathrm{~g}$ AgNPs-TAC/L and $\mathrm{pH}$ solution of 8 . The outcomes of initial phosphate concentrations and adsorption isotherm were found by mixing AgNPs-TAC at doses of $1.2 \mathrm{~g} / \mathrm{L}$ with $25 \mathrm{~mL}$ phosphate concentrations ranging from 10 to $100 \mathrm{mg} / \mathrm{L}$ over a period lasting $120 \mathrm{~min}$. 


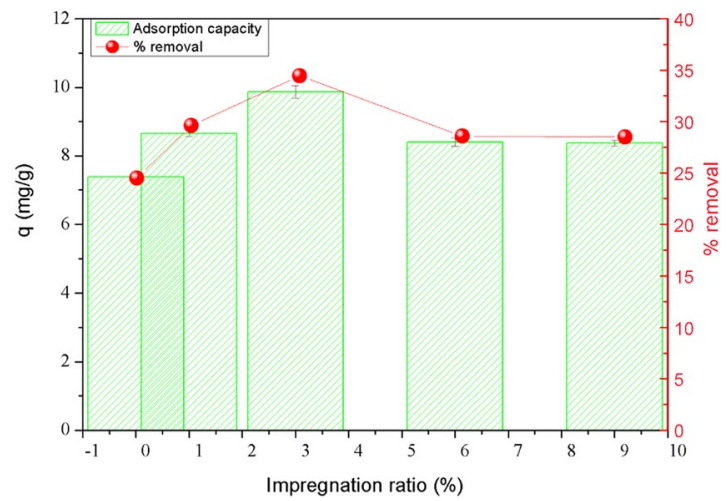

Figure 1. Effect of impregnation ratio of AgNPs and TAC on phosphate adsorption. Experimental conditions: initial phosphate concentration: $30 \mathrm{mg} / \mathrm{L}$, adsorbent dose: $1.2 \mathrm{~g}$ AgNPs-TAC/L, pH: 3, contact time: $60 \mathrm{~min}$, temperature: $25 \pm 2{ }^{\circ} \mathrm{C}$.

Characterization of AgNPs-TAC. The variation in the surficial morphologies of TAC and AgNPs-TAC was obtained from scanning electron microscope (SEM) images of energy dispersive X-ray spectroscopy (Hitachi S-4800) equipped with EDS and SEM systems. The crystalline structures of AgNPs-TAC were examined by X-ray diffraction pattern using XRD-D8 ADVANCE, with the $\mathrm{Cu}$ Ka radiation $(\lambda=1,5417 \AA)$. The presence of surface functional groups of AgNPs-TAC was detected using Fourier transform infrared spectroscopy (FT/IR-6300) in the $4000-500 \mathrm{~cm}^{-1}$ range. The $\mathrm{pH}$ at the point of zero charge $\left(\mathrm{pH}_{\mathrm{PZC}}\right)$ was determined by the shift method ${ }^{21}$. Determination of the surface area and the porous structure was conducted using Brunauer-Emmett-Teller (BET - BET, Builder, SSA-4300).

Measurements. The concentration of phosphate in the samples was determined by the Vanado-molybdo phosphoric acid method with an UV-Vis spectrophotometer ${ }^{22}$. The adsorption capacities of phosphate onto AgNPs-TAC at time $t\left(q_{t}, \mathrm{mg} / \mathrm{g}\right)$ and equilibrium $\left(\mathrm{q}_{\mathrm{e}}, \mathrm{mg} / \mathrm{g}\right)$ were calculated by Eqs. (1) and (2), respectively:

$$
\begin{aligned}
& q_{e}=\frac{\left(C_{o}-C_{e}\right) V}{W} \\
& q_{t}=\frac{\left(C_{o}-C_{t}\right) V}{W}
\end{aligned}
$$

where $C_{\mathrm{o}}(\mathrm{mg} / \mathrm{L}), C_{\mathrm{t}}(\mathrm{mg} / \mathrm{L})$, and $C_{\mathrm{e}}(\mathrm{mg} / \mathrm{L})$ are the phosphate concentrations in solution at beginning time, any time $t$, and equilibrium, respectively; $V(\mathrm{~L})$ is the working volume of phosphate solution; and $W(\mathrm{~g})$ is the dry weight of used AgNPs-AC.

Data analysis. All experiments were done in triplicate. All data statistics, comprising means, standard deviations, relative standard deviations and regressions (linear) were computed on SPSS software version 19.0. Wherever possible the error bars indicating the standard deviation are illustrated in the relevant figures.

\section{Results and Discussion}

Effect of impregnation ratio of AgNPs and TAC (AgNPs-TAC) on phosphate adsorption. To evaluate the effect of various impregnation ratios on phosphate adsorption capacity of modified TAC, the preliminary experiments were carried out with pristine TAC and TAC loaded by AgNPs at different AgNPs/TAC mass ratios $(1 \%, 3.0 \%, 6.0 \%$ and $9.0 \%)$. In this study, the experiment was carried out at initial phosphate concentration of $30 \mathrm{mg} / \mathrm{L}$, adsorption time of $60 \mathrm{~min}$, adsorbent dose of $1.2 \mathrm{~g} / \mathrm{L}$ at temperature of $25 \pm 2{ }^{\circ} \mathrm{C}$.

From Fig. 1, it can be seen that the AgNPs-TAC demonstrated a much better adsorption capacity for phosphate than the pristine TAC. The phosphate adsorption capacity increased from $7.38 \mathrm{mg} / \mathrm{g}$ to $9.87 \mathrm{mg} / \mathrm{g}$ when the impregnation ratio of AgNPs and TAC rose from $0 \%$ to $3.0 \%$. The presence of silver nanoparticles on the AgNPs-TAC surface could trigger a higher adsorption capacity. However, the phosphate adsorption capacity fell slightly to $9.40 \mathrm{mg} / \mathrm{g}$ and $9.38 \mathrm{mg} / \mathrm{g}$ when continuously elevating the impregnation ratio of TAC in AgNPs to $6 \%$ and $9 \%$, respectively. Furthermore the phosphate adsorption capacity did not increase when the impregnation ratio increased. This resulting trend is similar to that of a recent study on the removal of methylene blue using silver nanoparticles-loaded activated carbon derived from coconut shell ${ }^{16}$. According to the above finding, AgNPs-TAC with the impregnation ratio of 3\% gave the highest phosphate adsorption capacity. For this reason, it was chosen for material characterization and subsequent batch experiments.

Characterization of silver nanoparticles-loaded tea activated carbon (AgNPs-TAC). The surface structure is the important physical factor that affects the sorption capacity of TAC and AgNPs-TAC. The BET results (adsorption-desorption data) are presented in Fig. 2. The Brunauer-Emmett-Teller (BET) result reveals that the special surface area of TAC was $322 \mathrm{~m}^{2} / \mathrm{g}$. After loading silver nanoparticles, the surface area of 


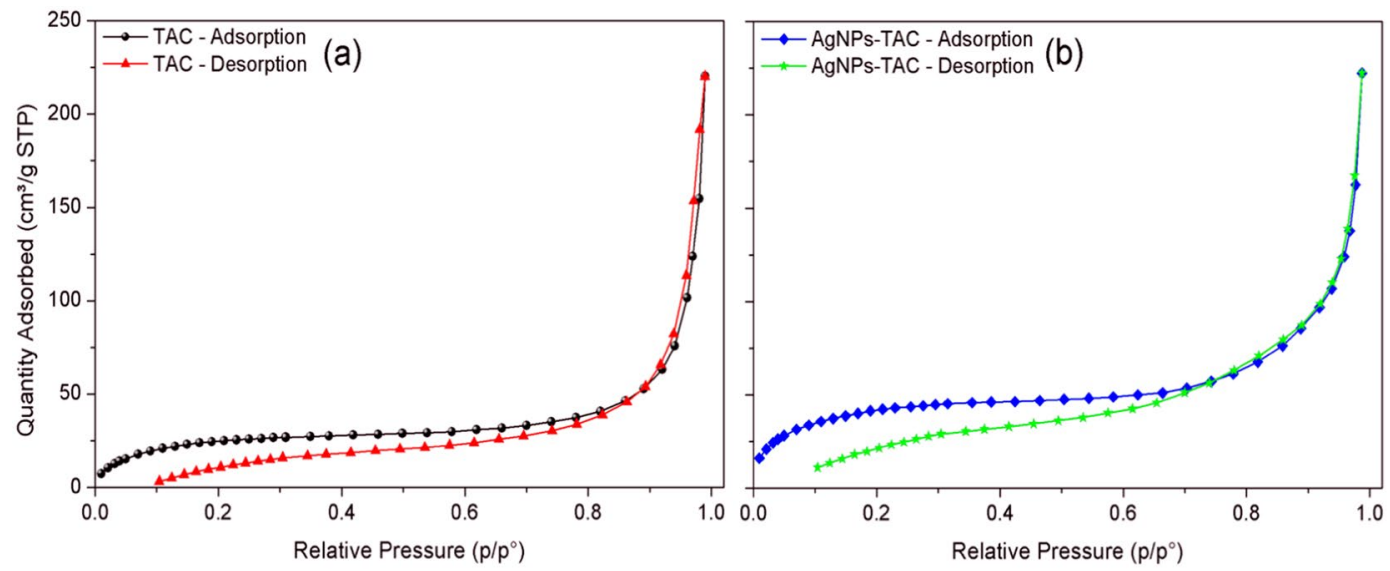

Figure 2. The BET results (adsorption-desorption data) of (a) TAC and (b) AgNPs-TAC.

new AgNPs-TAC slightly increased to $349 \mathrm{~m}^{2} / \mathrm{g}$. The average pore volume also rose from $0.0032 \mathrm{~cm}^{3} / \mathrm{g}$ to 0.0036 $\mathrm{cm}^{3} / \mathrm{g}$ for the TAC and AgNPs-TAC, respectively. The BET results indicated that the addition of AgNPs increased slightly the surface area and pore volume. The increase can be explained by an effective diffusion of AgNPs on the surface of TAC and the creation of new pores after coating of AgNPs on TAC ${ }^{23}$. The AgNPs were small particles which have higher surface area than that of TAC. The surface area and total pore volume of AgNPs-TAC may also be increased due to the nanostructure of $\mathrm{AgNPs}^{24}$. Increasing surface area and total pore volume of adsorbent due to modification processes confirmed the formation of new porous structures ${ }^{25}$. Results from EDS analysis (Fig. 3a) also indicated that the K element of TAC was released when loading AgNPs on TAC. The SEM image also showed the formation of AgNPs on the TAC (Fig. 4c,d). The surface physical morphology of AgNPs-TAC was clearly altered when white beads were present (Fig. 4c,d). These white beads did not appear in the SEM images of TAC (Fig. 4a,b), which suggests that the silver nanoparticles were distributed on the surface of AgNPs-TAC.

The elemental composition of the adsorbent before and after modification was determined by the EDS analysis. This finding indicates that the constituents of TAC included mainly C (72.91\%), O (26.17\%) and K (0.92\%) (Fig. 3a). For AgNPs-TAC, the proportions of elements of C, O and Ag were 72.34\%, 27.57\% and 0.09\%, respectively (Fig. 3b). This shows that silver nanoparticles were successfully attached on the TAC surface, which later affected phosphate adsorption. Moreover, the composition of AgNPs-TAC after phosphate adsorption reveals the presence of element P of $0.11 \%$ weight (Fig. 3c). It indicates that phosphate had been adsorbed on AgNPs-TAC.

The crystallinity of the TAC and AgNPs-TAC surface was characterized using a powder XRD analysis (Fig. 5a). The graph indicates that both TAC and AgNPs-TAC before and after phosphate adsorption included graphite crystal structure of diffraction peaks at 21.33 . This result also shows that after impregnation with AgNPs, the AgNPs-TAC's surface appeared to have silver nanoparticles at peaks of $37.88^{\circ}$ and $44.01^{\circ}$ (Fig. 5a). This proved to be similar to recent reports in which silver nanoparticles were loaded ont activated carbon at the peaks of $37.9^{\circ 26}$ and $44^{\circ 27}$.

The dominant functional groups on the TAC, AgNPs-TAC before and after phosphate adsorption were present as shown by FTIR spectra in Fig. 5b. From Fig. 5b, it can be seen that the broad peaks of $3851 \mathrm{~cm}^{-1}$, $3739 \mathrm{~cm}^{-1}$, and $3434 \mathrm{~cm}^{-1}$ were assigned to the $\mathrm{OH}$ stretching, which indicated compounds of phenols, alcohols and absorbed water ${ }^{28,29}$. The peaks at around $2922 \mathrm{~cm}^{-1}$ and $2855 \mathrm{~cm}^{-1}$ corresponded to the C-H stretching of alkanes and alkenes ${ }^{29}$. The $\mathrm{C}=\mathrm{O}$ stretching vibration in carbonyls appeared at peaks of $1698 \mathrm{~cm}^{-1}$ and $1692 \mathrm{~cm}^{-1}$, which confirmed the presence of carboxylic acids, lactone and carbonyl groups ${ }^{16,28}$. The peaks at $1531 \mathrm{~cm}^{-1}$ and $1458 \mathrm{~cm}^{-1}$ indicated the $\mathrm{C}=\mathrm{C}$ group of aromatic rings ${ }^{30}$.

The presence of the $\mathrm{C}-\mathrm{O}$ stretching group in acids, alcohols, phenols, ethers and esters can be recognized at peaks of $1320 \mathrm{~cm}^{-1}$ and $1058 \mathrm{~cm}^{-128}$. The peaks from $597 \mathrm{~cm}^{-1}$ to $869 \mathrm{~cm}^{-1}$ contributed to the C-H out-of-plane bending in benzene derivatives ${ }^{31}$. In AgNPs-TAC, the peaks at the $3434 \mathrm{~cm}^{-1}-3851 \mathrm{~cm}^{-1}$, around $2922 \mathrm{~cm}^{-1}$, $1531 \mathrm{~cm}^{-1}$ and $1058 \mathrm{~cm}^{-1}$ range became stronger than that in TAC. This reveals that the presence of $\mathrm{Ag}^{+}$ions affected functional groups on the AgNPs-TAC's surface. The point of zero charge $\left(\mathrm{pH}_{\mathrm{PZC}}\right)$ of TAC was 6.15 and $\mathrm{pH}_{\mathrm{PZC}}$ of AgNPs-TAC before and after phosphate adsorption were 6.52 and 6.58, respectively. Results indicate that $\mathrm{pH}_{\mathrm{PZC}}$ of AgNPs-TAC did not significantly change after the adsorption process.

Effect of $\mathrm{pH}$. The $\mathrm{pH}$ of the solution determines the presence of phosphate hydroxyl groups such as $\mathrm{H}_{3} \mathrm{PO}_{4}$, $\mathrm{H}_{2} \mathrm{PO}_{4}{ }^{-}, \mathrm{HPO}_{4}{ }^{2-}$ and $\mathrm{PO}_{4}{ }^{3-}$. This is one of the most important parameters influencing the adsorption process of phosphate $\mathrm{e}^{5,32}$. The effect of the solution $\mathrm{pH}$ on the phosphate adsorption of AgNPs-TAC was examined within a $\mathrm{pH}$ range of 3.0 to 10.0 and the results are shown in Fig. 6. It could be observed that the adsorption strongly depended on pH. From Fig. 6, as can be seen that the adsorption capacity of phosphate onto AgNPs-TAC decreased from 10.13 to 5.06 and the removal efficiency declined from $39.53 \%$ to $20.26 \%$ when pH increased from 3 to 10 . The adsorption capacity of phosphate decreased significantly when solution $\mathrm{pH}$ was more than 6 . A similar result on phosphate removal by $\mathrm{Zr} / \mathrm{Al}$-pillared montmorillonite was reported by Fang et al. ${ }^{33}$.

At different $\mathrm{pH}$ values, the phosphate can exist in different forms of $\mathrm{H}_{2} \mathrm{PO}_{4}^{-}, \mathrm{HPO}_{4}{ }^{2-}$, and $\mathrm{PO}_{4}{ }^{3-} 34$. In acidic conditions, the main phosphate species are monovalent $\mathrm{H}_{2} \mathrm{PO}_{4}{ }^{-}$and $\mathrm{HPO}_{4}{ }^{2-11}$. However, in alkaline conditions, the phosphate exists in the form of $\mathrm{PO}_{4}{ }^{3-}$. Moreover, the $\mathrm{pH}_{\mathrm{pzc}}$ values of the AgNPs-TAC were 6.52 and 6.58 


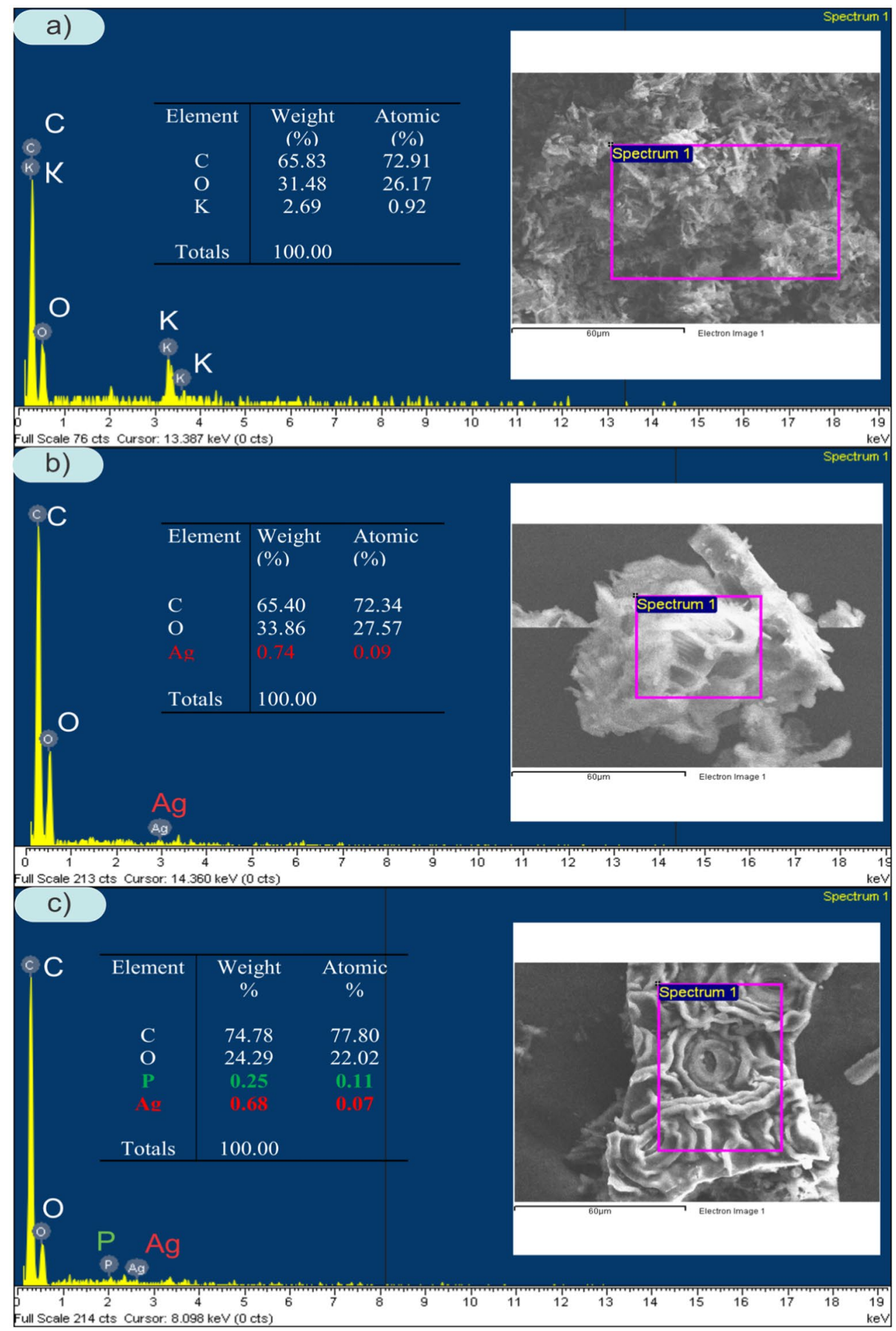

Figure 3. EDS spectra of TAC (a) and AgNPs-TAC before (b) and after phosphate adsorption (c).

before and after phosphate adsorption process, respectively. When solution $\mathrm{pH}$ was higher than the $\mathrm{pH}_{\mathrm{pzc}}$ value of the AgNPs-TAC, the surface of AgNPs-TAC was positively charged. However, the phosphate adsorption capability of AgNPs-TAC decreased with the increase in solution $\mathrm{pH}$. It suggests that electrostatic attraction was not the main phosphate removal mechanism. The competition of $\mathrm{OH}^{-}$with $\mathrm{PO}_{4}{ }^{3-}$ in alkaline conditions could also contribute to a loss of phosphate adsorption onto AgNPs-TAC when increasing solution $\mathrm{pH}$.

Effect of contact time. Adsorption experiments were carried out at different contact times from 5 to $240 \mathrm{~min}$ with the initial phosphate concentration of $30 \mathrm{mg} / \mathrm{L}$, adsorbent dose of $1.2 \mathrm{mg} / \mathrm{L}$ at solution $\mathrm{pH}$ of 3 and room temperature $\left(25 \pm 2^{\circ} \mathrm{C}\right)$. Results from Fig. 7 show that the adsorption capacity of phosphate increased 

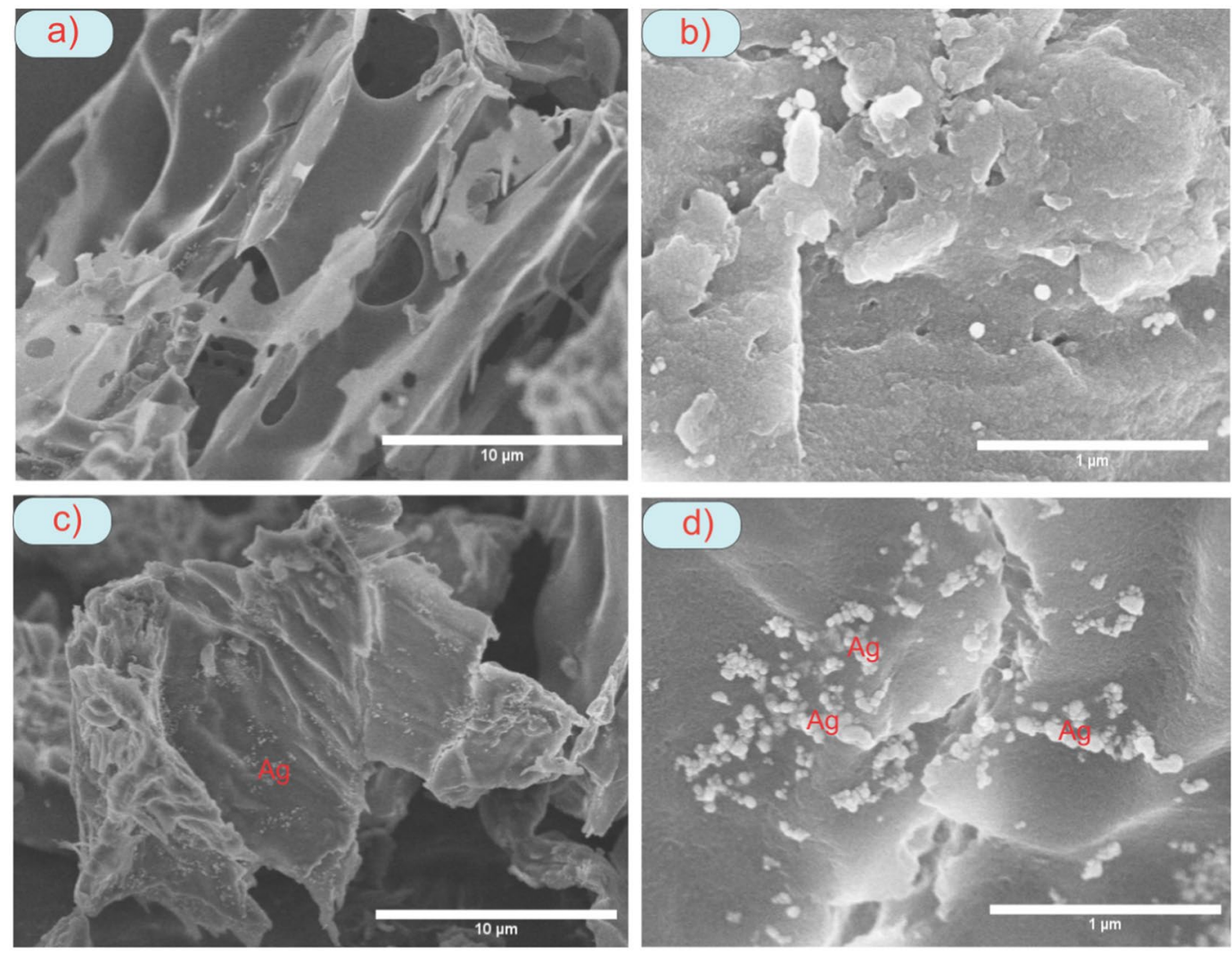

Figure 4. SEM image of (a,b) TAC and (c,d) AgNPs-TAC.
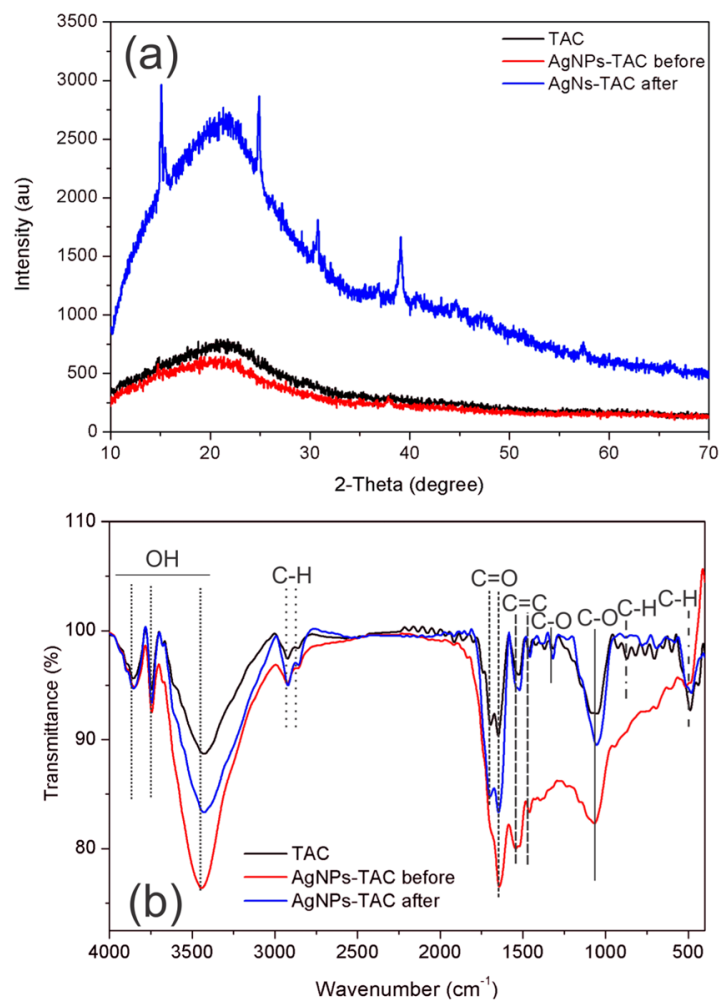

Figure 5. Graph of XRD (a) and FTIR (b) of TAC and AgNPs-TAC before and after phosphate adsorption. 

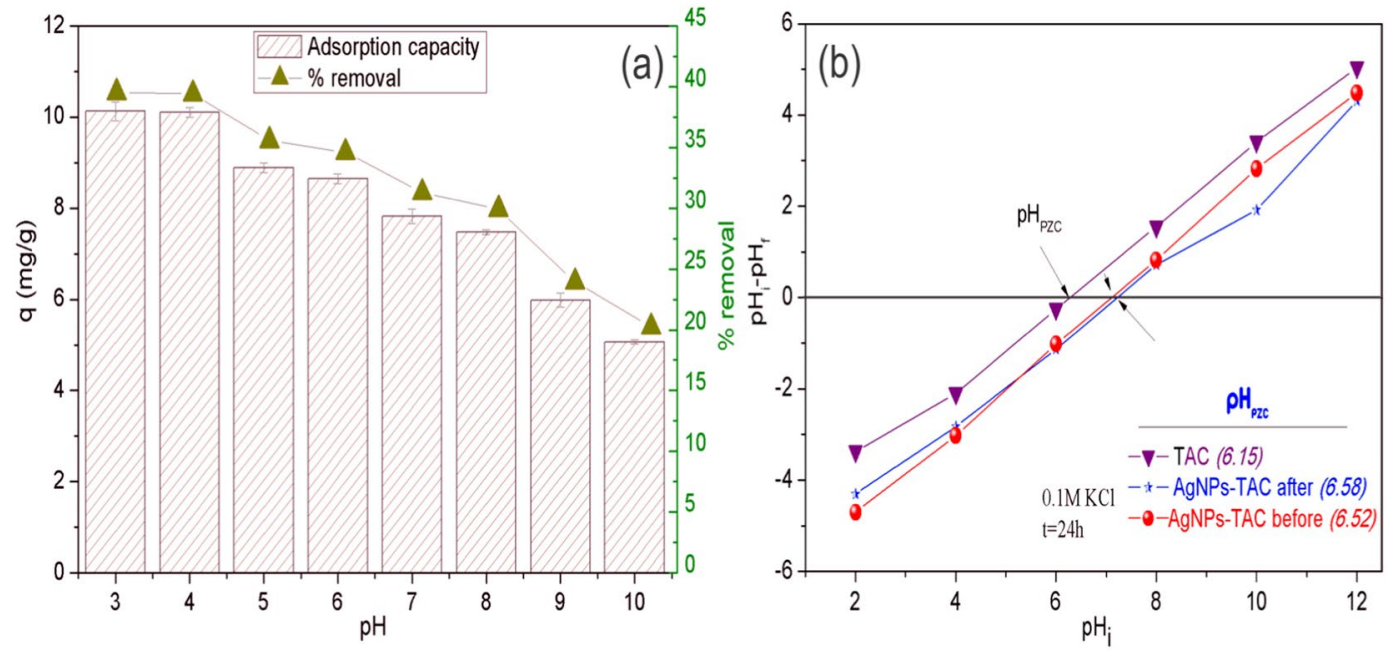

Figure 6. (a) Effect of $\mathrm{pH}$ on phosphate adsorption. Experimental conditions: initial phosphate concentration: $30 \mathrm{mg} / \mathrm{L}$, adsorbent dose: $1.2 \mathrm{~g}$ AgNPs-TAC/L, contact time: $60 \mathrm{~min}$, temperature: $25 \pm 2{ }^{\circ} \mathrm{C}$ and $(\mathbf{b}) \mathrm{pH}_{\mathrm{PZC}}$ of AgNPs-TAC.

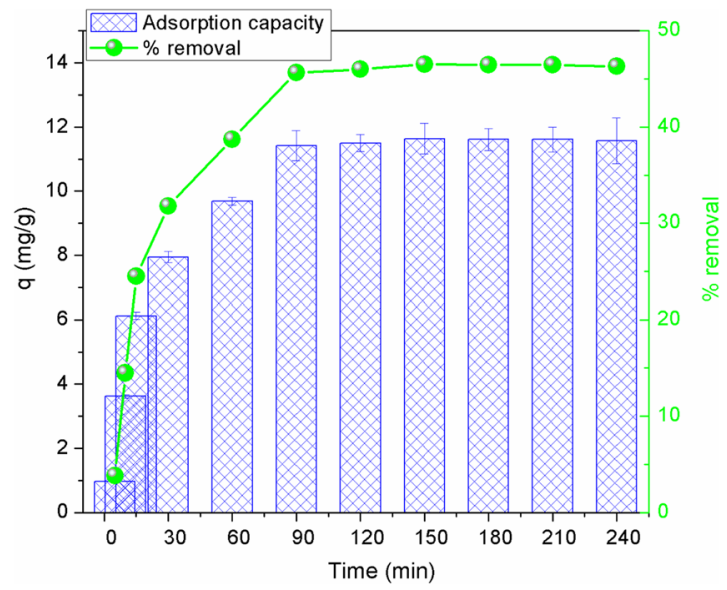

Figure 7. Effect of contact time on phosphate adsorption onto AgNPs-TAC. Experimental conditions: initial phosphate concentration: $30 \mathrm{mg} / \mathrm{L}$, adsorbent dose: $1.2 \mathrm{~g}$ AgNPs-TAC/L, $\mathrm{pH}: 3$, temperature: $25 \pm 2{ }^{\circ} \mathrm{C}$.

rapidly, from $0.96 \mathrm{mg} / \mathrm{g}$ to $11.50 \mathrm{mg} / \mathrm{g}$ when increasing contact time from 30 to $120 \mathrm{~min}$ (corresponding to phosphate removal rate rose from $3.8 \%$ to $46 \%$ ). In this experimental scenario, the adsorption process slowed down after $120 \mathrm{~min}$ and became stable after $150 \mathrm{~min}$. Adsorption capacity and the efficiency in removing phosphate were achieved the highest values of $11.63 \mathrm{mg} / \mathrm{g}$ and $46.53 \%$, respectively, at $150 \mathrm{~min}$ contact time. In the initial stage, the AgNPs-TAC' surface had a large number of fresh available binding sites leading to a rapid increase in adsorption $^{6}$. Over a period of time, the adsorption process become slower and stable due to: firstly, the saturation of adsorption active sites on the surface of AgNPs-TAC; and secondly, gradual reduction in the concentration gradient between the bulk solution and adsorbent ${ }^{1}$. This trend was similar to results for other studies that looked at phosphate adsorption from aqueous solution ${ }^{34,35}$.

Effect of absorbent dose. To examine the possible effects of adsorbent dose on the phosphate adsorption of AgNPs-TAC, experiments were conducted at different dosages ranging from 0.4 to $8.4 \mathrm{~g} / \mathrm{L}$. Experiments were carried out at the optimum $\mathrm{pH}$ of 3.0, contact time lasting $120 \mathrm{~min}$ and initial phosphate concentration of $30 \mathrm{mg} / \mathrm{L}$. The results are shown in Fig. 8. It could be observed that the adsorption percentage of phosphate increased from $21.2 \%$ to $60.2 \%$, which corresponded to the AgNPs-TAC dose ranging from 0.4 to $4.8 \mathrm{~g} / \mathrm{L}$. Its increase could be caused by the increase in the available surface area and active sites for adsorption when raising the dose of AgNPs-TAC 6 . However, the removal efficiency of phosphate did not increase and remained stable when the dose rose from 4.8 to $8.4 \mathrm{~g} / \mathrm{L}$. Moreover, the adsorption capacity of phosphate onto AgNPs-TAC tended to decrease from $15.90 \mathrm{mg} / \mathrm{g}$ to $2.15 \mathrm{mg} / \mathrm{g}$ when the AgNPs-TAC dosage rose from 0.4 to $8.4 \mathrm{~g} / \mathrm{L}$. The decline in adsorption capacity at a higher adsorbent dose might be due to aggregation of AgNPs-TAC particles which reduced the effective surface area and active sites for phosphate adsorption ${ }^{36}$. Here, the aggregation at higher adsorbent dose 


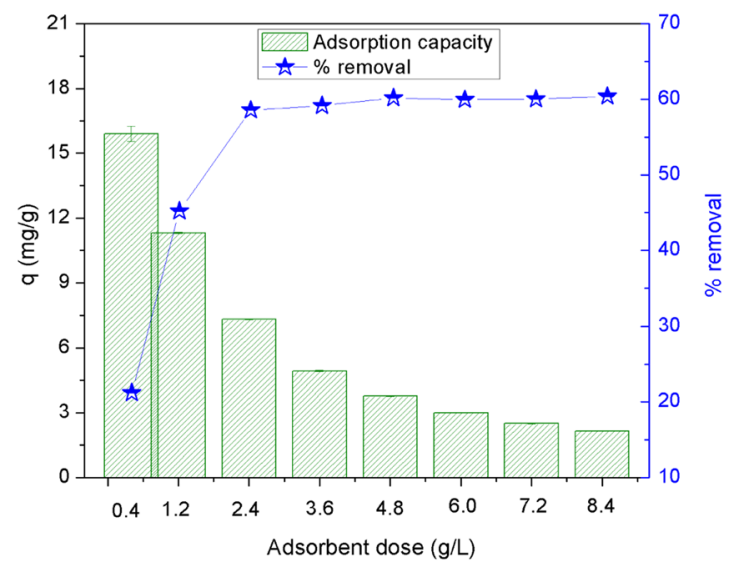

Figure 8. Effect of AgNPs-TAC dosage on phosphate adsorption. Experimental conditions: $\mathrm{pH}$ : 3, contact time: $150 \mathrm{~min}$, initial concentration of $\mathrm{PO}_{4}{ }^{3-}: 30 \mathrm{mg} / \mathrm{L}$, temperature: $25 \pm 2^{\circ} \mathrm{C}$.

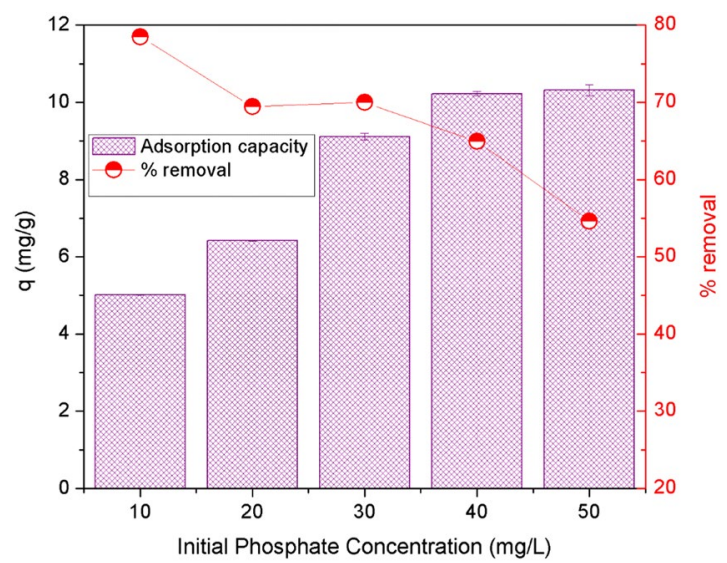

Figure 9. Effect of initial phosphate concentrations on the adsorption capacity by AgNPs-TAC. Experimental conditions: solution $\mathrm{pH}: 3$, contact time: $150 \mathrm{~min}$, adsorbent dose: $1.2 \mathrm{~g}$ AgNPs-TAC/L solution, temperature: $25 \pm 2{ }^{\circ} \mathrm{C}$.

of AgNPs-TAC at a certain initial phosphate concentration and solution volume led to an increase in the unsaturation of sorption sites on AgNPs-TAC surface. It triggered a decrease in adsorption capacity ${ }^{37}$. These results are in line with other studies which indicated that adsorbent dose plays a vital role in the adsorption process ${ }^{38,39}$.

Effect of initial phosphate concentration. The initial concentration of adsorbate extremely influenced the adsorption process. The effect of initial phosphate concentration was investigated at different initial phosphate concentrations from 10 to $50 \mathrm{mg} / \mathrm{L}$ at optimum $\mathrm{pH}$ of 3 , adsorbent dosage of $1.2 \mathrm{~g} / \mathrm{L}$ and contact time of 120 min. Results (Fig. 9) show that the adsorption capacity of phosphate on AgNPs-TAC increased significantly as the initial phosphate concentration rose from $10 \mathrm{mg} / \mathrm{L}$ to $40 \mathrm{mg} / \mathrm{L}$ and became stable at a higher concentration. The adsorption capacity reached a maximum of $10.23 \mathrm{mg} / \mathrm{g}$ at the initial phosphate concentration of $40 \mathrm{mg} / \mathrm{g}$. Meanwhile, the removal efficiency of phosphate fell from $78.50 \%$ to $54.62 \%$, which corresponded with an increase in the initial phosphate concentration from $10 \mathrm{mg} / \mathrm{L}$ to $50 \mathrm{mg} / \mathrm{L}$. This is due to the fact that at a lower concentration, almost all phosphate ions interacted with available binding sites. At a higher initial phosphate concentration, the binding sites became saturated and adsorption capacity did not rise further at the higher initial phosphate concentration $^{6}$. Furthermore, when the adsorbent mass and volume of solution were unchanged, the ratio of active sites to the phosphate ions concentration became lower at a higher initial concentration. This led to a decrease in the percentage of phosphate removed ${ }^{36}$. Similar results have been reported elsewhere ${ }^{6,28}$.

Adsorption isotherm. To further understand the adsorption of phosphate on AgNPs-TAC, three isotherm models, namely the Langmuir, Freundlich and Sips were employed to describe the adsorption isotherm. The Langmuir model presumes that a monolayer adsorption process takes place on a homogenous surface and adsorption energy of all active sites is always similar ${ }^{40}$. The Freundlich model assumes that multilayer adsorption occurs on a heterogeneous surface and all the adsorption locations have different affinities ${ }^{6}$. The Sips model is a combination of the Freundlich and Langmuir models ${ }^{41}$. The equations for the Langmuir, Freundlich and Sips models are shown below in Eqs. (3), (4) and (5), respectively: 


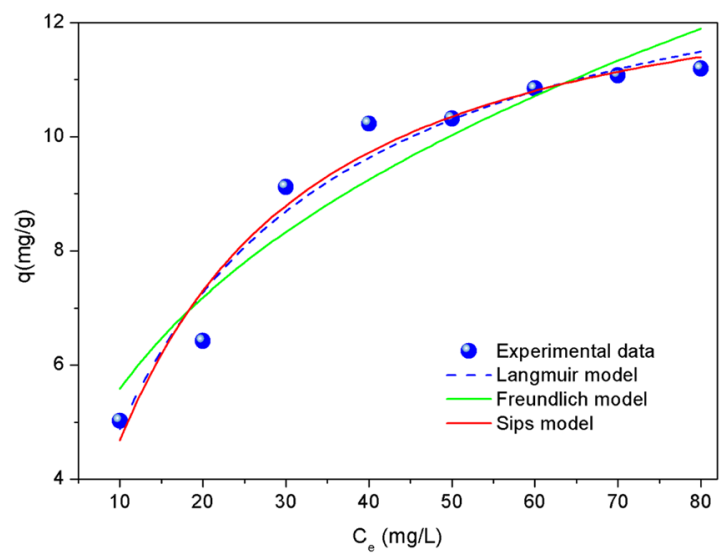

Figure 10. Adsorption isotherm of phosphate on AgNPs-TAC at contact time of $120 \mathrm{~min}$, AgNPs-TAC dose of $1.2 \mathrm{~g} / \mathrm{L}$, solution $\mathrm{pH}: 3$ and adsorbent dose: $1.2 \mathrm{~g}$ AgNPs-TAC/L.

\begin{tabular}{|c|c|c|c|c|c|c|c|c|c|c|}
\hline \multicolumn{3}{|c|}{ Langmuir model } & \multicolumn{3}{|c|}{ Freundlich model } & \multicolumn{4}{|c|}{ Sips model } & \multirow[b]{2}{*}{$q_{\operatorname{mexp}}(\mathrm{mg} / \mathrm{g})$} \\
\hline$q_{m}(\mathrm{mg} / \mathrm{g})$ & $K_{L}$ & $R^{2}$ & $K_{F}$ & $1 / n$ & $R^{2}$ & $q_{m}(\mathrm{mg} / \mathrm{g})$ & $1 / n$ & $b$ & $R^{2}$ & \\
\hline 13.62 & 0.052 & 0.957 & 0.916 & 0.363 & 0.902 & 13.22 & 1.172 & \begin{tabular}{|l|}
0.0369 \\
\end{tabular} & 0.951 & 11.19 \\
\hline
\end{tabular}

Table 1. Adsorption isotherm parameters and correlation coefficients of the Langmuir, Freundlich and Sips models for phosphate adsorption on AgNPs-TAC.

$$
\begin{gathered}
q_{e}=\frac{q_{m} K_{L} C_{e}}{1+K_{L} C_{e}} \\
q_{e}=K_{F} C_{e}^{\frac{1}{n}} \\
q_{e}=\frac{q_{m}\left(b C_{e}\right)^{\frac{1}{n}}}{1+\left(b C_{e}\right)^{\frac{1}{n}}}
\end{gathered}
$$

where $q_{e}(\mathrm{mg} / \mathrm{g})$ and $q_{m}(\mathrm{mg} / \mathrm{g})$ are the adsorption capacity at equilibrium and the maximum saturated adsorption capacity; $C_{e}(\mathrm{mg} / \mathrm{L})$ is the adsorbate concentration at equilibrium; $K_{L}(\mathrm{~L} / \mathrm{mg})$ is the Langmuir constant related to the energy of the adsorption; and $K_{F}(\mathrm{mg} / \mathrm{g})$ is the Freundlich constant, which characterizes the strength of adsorption.

The fitting results for the experimental data of phosphate adsorption on AgNPs-TAC by Langmuir, Freundlich and Sips models are shown in Fig. 10 and isotherm parameters are presented in Table 1. It can be observed that the adsorption data fitted well to the Langmuir, Freundlich and Sips models with the interrelated coefficients values $\left(R^{2}\right)$ of $0.957,0.902$ and 0.951 , respectively. It indicates that the Langmuir and Sips models did fit better than the Freundlich model for isotherm adsorption of phosphate on AgNPs-TAC. $\mathrm{Q}_{\mathrm{m}}$ values determined by the Langmuir and Sips model were $13.62 \mathrm{mg} / \mathrm{g}$ and $13.22 \mathrm{mg} / \mathrm{g}$, respectively, which were closer to the experimental value $\left(\mathrm{q}_{\operatorname{mexp}} 11.19 \mathrm{mg} / \mathrm{g}\right)$. It indicates that the main adsorption occurred on the monolayer or through a fixed number of identical sites on the AgNPs-TAC surface. Here, the 1/n value calculated from the Freundlich model was 0.306. It indicates that the phosphate adsorption onto AgNPs-TAC was favorable. A similar trend was reported for the removal of $\mathrm{Cr}(\mathrm{VI})$ by magnetic biochar ${ }^{42}$ and magnetite nanoparticles ${ }^{43}$.

Adsorption kinetics of phosphate on AgNPs-TAC. In order to describe the kinetics of phosphate adsorption on AgNPs-TAC, two kinetics models including pseudo-first-order (Eq. 6) and pseudo-second-order (Eq. 7) models were used.

$$
\begin{gathered}
q_{t}=q_{e}\left(1-\mathrm{e}^{-k_{1} t}\right) \\
q_{t}=\frac{q_{e}^{2} k_{2} t}{1+q_{e} k_{2} t}
\end{gathered}
$$

Where, $\mathrm{q}_{\mathrm{e}}$ and $\mathrm{q}_{\mathrm{t}}$ are the adsorption capacity at equilibrium and at time $\mathrm{t}(\mathrm{mg} / \mathrm{g}) ; \mathrm{k}_{1}$ is the first-order rate constant $\left(\mathrm{min}^{-1}\right) ; \mathrm{k}_{2}$ is the second-order rate constant, $\mathrm{g} / \mathrm{mg} . \mathrm{min} ; \alpha$ is the initial adsorption rate ( $\left.\mathrm{mg} / \mathrm{g} \mathrm{min}\right)$; and $\beta$ is the adsorption constant $(\mathrm{g} / \mathrm{mg})$. 


\begin{tabular}{|c|c|c|c|c|c|c|}
\hline \multicolumn{3}{|c|}{ Pseudo-first order } & \multicolumn{3}{|c|}{ Pseudo-second order } & \multirow[b]{2}{*}{$q_{e, \exp }(\mathrm{mg} / \mathrm{g})$} \\
\hline $\mathbf{q}_{\mathrm{m}, \mathrm{cal}}(\mathrm{mg} / \mathrm{g})$ & $K_{1}(1 / \mathrm{min})$ & $\mathbf{R}^{2}$ & $\mathbf{q}_{\mathrm{m}, \mathrm{cal}}(\mathrm{mg} / \mathrm{g})$ & $\mathrm{K}_{2}(\mathrm{~g} / \mathrm{mg} \times \mathbf{m i n})$ & $\mathbf{R}^{2}$ & \\
\hline 11.57 & 0.0386 & $\begin{array}{ll} \\
\end{array}$ & 13.24 & 0.0034 & 0.966 & 11.63 \\
\hline
\end{tabular}

Table 2. Kinetics parameters for phosphate adsorption on AgNPs-TAC.

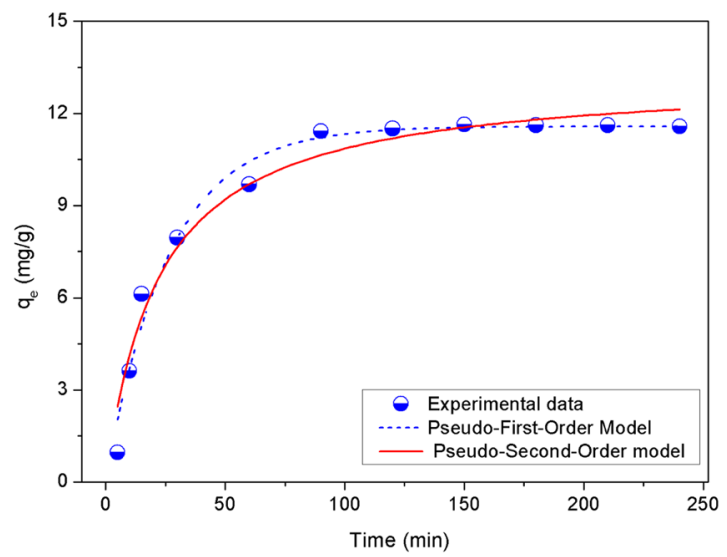

Figure 11. Kinetics models of phosphate adsorption on AgNPs-TAC with initial phosphate concentration of $30 \mathrm{mg} / \mathrm{L}$, adsorbent dose of $1.2 \mathrm{~g} / \mathrm{L}$, solution $\mathrm{pH}: 3$ and contact time of $120 \mathrm{~min}$.

The corresponding kinetics parameters and prediction curves of the two kinetics models are presented in Table 2 and Fig. 11, respectively. The high values of linear regression coefficient ( $\mathrm{R}^{2}$ from 0.978 to 0.966 ) indicate the phosphate adsorption onto AgNPs-TAC fit well to both models. Correlation coefficient of the pseudo-first-order model $\left(\mathrm{R}^{2}=0.978\right)$ was slightly higher than that of the pseudo-second-order model $\left(\mathrm{R}^{2}\right.$ $=0.966)$. Additionally, the maximum adsorption capacity $\left(\mathrm{q}_{\mathrm{m}}\right)$ calculated from the pseudo-first-order model $(11.57 \mathrm{mg} / \mathrm{g})$ and the pseudo-second-order model $(13.24 \mathrm{mg} / \mathrm{g})$ were relatively close to the experimental data $(11.63 \mathrm{mg} / \mathrm{g})$. These results indicated that both pseudo-first-order and pseudo-second-order models could describe the adsorption kinetics of phosphate on AgNPs-TAC. They also illustrated that chemical sorption was the main mechanism for phosphate adsorption on AgNPs-TAC which involves valence forces through sharing or exchange of electrons between the adsorbate and adsorbent ${ }^{2}$. These results are similar to what is documented in previous studies on phosphate adsorption using other adsorbents ${ }^{6,33}$.

Discussion of AgNPs-TAC role in phosphate adsorption. The adsorption mechanisms of phosphate by activated carbon were affected by the surface properties of AgNPs-TAC. The main operating mechanism of phosphate by AgNPs-TAC was the ion exchange process. To identify phosphate adsorption mechanisms on TAC and AgNPs-TAC samples were characterized by BET, SEM, XRD, FTIR and EDS. Results of the BET analysis show that the AgNPs-TAC led to a negligible increase in surface area $\left(348 \mathrm{~m}^{2} / \mathrm{g}\right)$ and pore volume $\left(0.0036 \mathrm{~cm}^{3} / \mathrm{g}\right)$ than TAC $\left(321.75 \mathrm{~m}^{2} / \mathrm{g}\right.$ and $0.0032 \mathrm{~cm}^{3} / \mathrm{g}$, respectively). The increase of surface area and number of active sites due to the coating of Ag nanoparticles on activated carbon (AgNPs-TAC) led to the increase in phosphate adsorption on AgNPs-TAC. The XRD analysis also revealed that the AgNPs loaded successful on the TAC surface. The presence of $\mathrm{Ag}^{+}$ions affected functional groups located on the AgNPs-TAC's surface, and this was further confirmed through the bigger peaks of AgNPs-TAC in the following ranges: $3434 \mathrm{~cm}^{-1}$ to $3851 \mathrm{~cm}^{-1}, 2922 \mathrm{~cm}^{-1}, 1531 \mathrm{~cm}^{-1}$ and $1058 \mathrm{~cm}^{-1}$.

The good fit of the experimental data to the adsorption kinetics and isotherm models also confirmed that the removal of phosphate by AgNPs-TAC occurred through chemisorption. The adsorption process resulted in the formation of coulombic attraction between phosphate anions and the binding sites of AgNPs-TAC. This was proven by the presence of $\mathrm{P}$ on the surface of AgNPs-TAC (Fig. 3c). At pH of 3, the phosphate exist in the form of dihydrogen phosphate ions $\left(\mathrm{H}_{2} \mathrm{PO}_{4}^{-}\right)$and the surface complex is protonated. Thus, the possible complexes were $\mathrm{Ag}(\mathrm{PO})(\mathrm{OH}), \mathrm{Ag}_{2} \mathrm{P}(\mathrm{OH})_{2}$, and/or $\mathrm{Ag}_{2}(\mathrm{PO})(\mathrm{OH})_{2}$. The form of $\mathrm{H}_{2} \mathrm{PO}_{4}{ }^{-}$could also combine with $\mathrm{Ag}^{+}$to form $\mathrm{Ag}_{2} \mathrm{P}$ precipitate. It is observed that the peak of silver nanoparticles was changed from weak at $37.88^{\circ}$ to stronger at $39.13^{\circ}$ for AgNPs-TAC before and after phosphate adsorption process. This may be due to the possible complexes of silver nanoparticles and phosphate. Moreover, at low $\mathrm{pH}$ surface hydroxyl groups of AgNPs-TAC were protonated in the ligand exchange process and $-\mathrm{OH}^{2+}$ was to displace easily from the metal binding sites ${ }^{44}$. Thus, ligand exchange was also one of mechanisms of phosphate adsorption onto AgNPs-TAC. For AgNPs-TAC, after phosphate adsorption, two peaks at $1698 \mathrm{~cm}^{-1}, 1320 \mathrm{~cm}^{-1}$, and some peaks around $597 \mathrm{~cm}^{-1}$ to $869 \mathrm{~cm}^{-1}$ were virtually disappeared. This obviously indicates that some surface groups of the adsorbent were replaced by phosphate. Therefore, the complexes and ligand exchange were the main mechanisms of the phosphate adsorption onto AgNPs-TAC. This agreed with the previous report that anionic coordination exchange adsorption was the main mechanism of phosphate adsorption onto modified bentonite granular $(\mathrm{MBG})^{45}$. 


\begin{tabular}{|l|l|l|l|}
\hline Adsorbsent & $\begin{array}{l}\text { Equilibrium phosphate } \\
\text { concentration range (mg/L) }\end{array}$ & $\begin{array}{l}\text { Langmuir maximum } \\
\text { adsorption capacity (mg/g) }\end{array}$ & References \\
\hline AgNPs-TAC & $0-50$ & 13.62 & This study \\
\hline Fly ash (FA)/biochar composite & $0-25$ & 3.20 & 26 \\
\hline $\begin{array}{l}\text { Carboxymethyl konjac glucomannan loaded } \\
\text { with lanthanum }\end{array}$ & $0-16$ & 17.156 & 4 \\
\hline Zr/Al-pillared montmorillonite & $0-15$ & 17.2 & 28 \\
\hline Activated laterite & $0-25$ & 1.86 & 37 \\
\hline Lanthanum doped vesuvianite & $0-4$ & 6.7 & 38 \\
\hline Red mud with HCl acid treatment & $0-1$ & 0.58 & 39 \\
\hline Palygorskite with acid and thermal treatment & $0-150$ & 8.31 & 40 \\
\hline
\end{tabular}

Table 3. Comparison of AgNPs-TAC with other adsorbents for phosphate adsorption capacity.

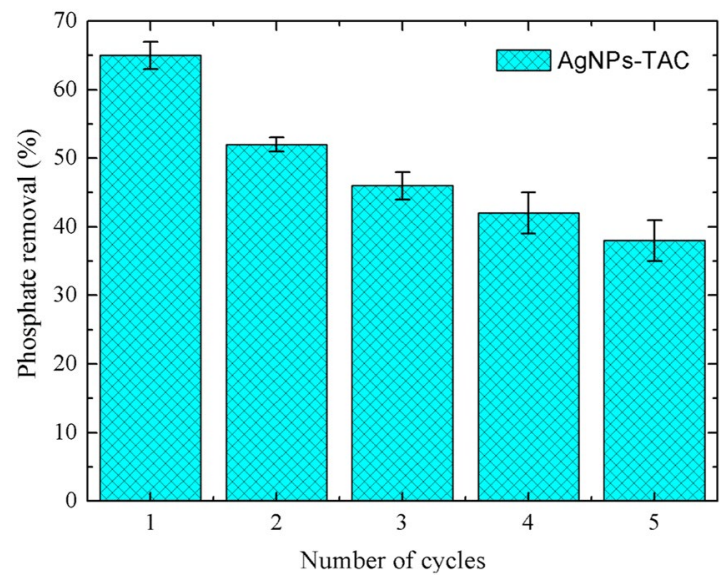

Figure 12. Phosphate percentage removal of AgNPs-TAC after regeneration by $\mathrm{NaOH} 1 \mathrm{M}$. Initial phosphate concentration of $30 \mathrm{mg} / \mathrm{L}$, adsorbent dose of $1.2 \mathrm{~g} / \mathrm{L}$, solution $\mathrm{pH}: 3$ and contact time of $120 \mathrm{~min}$.

To assess phosphate adsorption, the results documented in this study were compared with other adsorbents. The findings for phosphate adsorption with various other types of adsorbents noted in seven studies are presented in Table 3. The data in Table 3 showed that phosphate adsorption capacity of AgNPs-TAC was higher than that of fly ash (FA)/biochar composite, Lanthanum doped vesuvianite, activated laterite, Palygorskite with acid and thermal treatment and red mud with $\mathrm{HCl}$ acid treatment. However, the adsorption capacity of AgNPs-TAC for phosphate was lower than that of $\mathrm{Zr} / \mathrm{Al}$-pillared montmorillonite, carboxymethyl konjac glucomannan loaded with lanthanum. This indicated that AgNPs-TAC is a potentially effective and low-cost adsorbent for removing phosphate from aqueous solutions.

Reusability. The reusability of AgNPs-TAC was evaluated by regeneration of P-loaded AgNPs-TAC after adsorption. AgNPs-TAC was firstly separated by filtration after the batch adsorption experiment. The active sites on the surface of AgNPs-TAC were then regenerated by mixing $0.1 \mathrm{~g}$ of P-loaded AgNPs-TAC with $25 \mathrm{~mL} \mathrm{NaOH}$ $1 \mathrm{M}$ during $24 \mathrm{~h}$. Finally, samples were dried at $80^{\circ} \mathrm{C}$ under vacuum condition before reusing in the batch study. Figure 12 presents the result of the reusability of AgNPs-TAC for phosphate adsorption. From Fig. 12, phosphate adsorption efficiency onto AgNPs-TAC decreased gradually in the consecutive five regeneration cycles, from $65.39 \%$ (first adsorption) to $38.26 \%$ (after five cycles). The decrease of adsorption efficiency could be caused by the loss of functional groups and incomplete desorption ${ }^{46}$. This result indicates that AgNPs-TAC can be reusable for phosphate removal from water and wastewater within limited times.

\section{Conclusions}

AgNPs-TAC was composited for the first time as an adsorbent for phosphate removal from aqueous solution. The phosphate adsorption process on AgNPs-TAC greatly depended on $\mathrm{pH}$ value. In this study, the $\mathrm{pH}$ of 3 was the best one for the adsorption of phosphate on AgNPs-AC. This result indicates that adsorption capacity of phosphate on AgNPs-AC increased when the AgNPs-TAC dose and contact time also increased. The maximum adsorption capacity of phosphate by AgNPs-TAC was $13.62 \mathrm{mg} / \mathrm{g}$ at an initial phosphate concentration of $30 \mathrm{mg} / \mathrm{L}$. As well, the Langmuir and Sips models were suitable models for describing the adsorption isotherm of phosphate on AgNPs-TAC. The pseudo-first-order and pseudo-second-order models had the best fit for the adsorption kinetics of phosphate on AgNPs-TAC with high correlation coefficients of 0.978 and 0.966 , respectively. Finally, the main mechanism of phosphate adsorption onto AgNPs-TAC was ion exchange, evidenced by the sharing or exchange of electrons between the adsorbate and adsorbent. 
Received: 8 December 2019; Accepted: 11 February 2020;

Published online: 27 February 2020

\section{References}

1. Jung, K. W., Lee, S. \& Lee, Y. J. Synthesis of novel magnesium ferrite $(\mathrm{MgFe} 2 \mathrm{O} 4) /$ biochar magnetic composites and its adsorption behavior for phosphate in aqueous solutions. Bioresour. Technol. 245, 751-759 (2017).

2. Vikrant, K. et al. Engineered/designer biochar for the removal of phosphate in water and wastewater. Sci. Total Environ. 616-617, $1242-1260$ (2018).

3. Böttger, S. A. \& McClintock, J. B. Effects of inorganic and organic phosphate exposure on aspects of reproduction in the common sea urchin Lytechinus variegatus (Echinodermata: Echinoidea). J. Exp. Zool. 292, 660-671 (2002).

4. Böttger, S. A. \& McClintock, J. B. The effects of chronic inorganic and organic phosphate exposure on bactericidal activity of the coelomic fluid of the sea urchin Lytechinus variegatus (Lamarck) (Echinodermata: Echinoidea). Comp. Biochem. Physiol. - C Toxicol. Pharmacol. 150, 39-44 (2009).

5. Ren, Z., Shao, L. \& Zhang, G. Adsorption of phosphate from aqueous solution using an iron-zirconium binary oxide sorbent. Water, Air Soil Pollut. 223, 4221-4231 (2012).

6. Zhang, X. et al. Adsorption of phosphorus from slaughterhouse wastewater by carboxymethyl konjac glucomannan loaded with lanthanum. Int. J. Biol. Macromol. 119, 105-115 (2018).

7. Yin, Q., Ren, H., Wang, R. \& Zhao, Z. Evaluation of nitrate and phosphate adsorption on Al-modified biochar: Influence of Al content. Sci. Total Environ. 631-632, 895-903 (2018).

8. Su, Y., Yang, W., Sun, W., Li, Q. \& Shang, J. K. Synthesis of mesoporous cerium-zirconium binary oxide nanoadsorbents by a solvothermal process and their effective adsorption of phosphate from water. Chem. Eng. J. 268, 270-279 (2015).

9. Y.Wang, D. S. Phosphate removal from aqueous solutions on fly ash with medium calcium content. Korean J. Chem. Eng. 32, 1323-1326 (2015).

10. Lürling, M., Waajen, G. \& van Oosterhout, F. Humic substances interfere with phosphate removal by lanthanum modified clay in controlling eutrophication. Water Res. 54, 78-88 (2014).

11. Liu, J., Zhou, Q., Chen, J., Zhang, L. \& Chang, N. Phosphate adsorption on hydroxyl-iron-lanthanum doped activated carbon fiber. Chem. Eng. J. 215-216, 859-867 (2013).

12. Jack, J., Huggins, T. M., Huang, Y., Fang, Y. \& Ren, Z. J. Production of magnetic biochar from waste-derived fungal biomass for phosphorus removal and recovery. J. Clean. Prod. 224, 100-106 (2019).

13. Sadegh, H. et al. The role of nanomaterials as effective adsorbents and their applications in wastewater treatment. J. Nanostruc. Chem. 7, 1-14 (2017).

14. Al-Qahtani, K. M. Cadmium removal from aqueous solution by green synthesis zero valent silver nanoparticles with Benjamina leaves extract. Egypt. J. Aquat. Res. 43, 269-274 (2017).

15. Azeez, L., Lateef, A., Adebisi, S. A. \& Oyedeji, A. O. Novel biosynthesized silver nanoparticles from cobweb as adsorbent for Rhodamine B: equilibrium isotherm, kinetic and thermodynamic studies. Applied Water Sci. 8, 32 (2018).

16. Van, H. T. et al. Applying Activated Carbon Derived from Coconut Shell Loaded by Silver Nanoparticles to Remove Methylene Blue in Aqueous Solution. Water. Air. Soil Pollut. 229, 232 (2018).

17. Mortazavi, K., Rajabi, H., Ansari, A., Ghaedi, M. \& Dashtian, K. Preparation of silver nanoparticle loaded on activated carbon and its application for removal of malachite green from aqueous solution. Synth. React. Inorganic, Met. Nano-Metal Chem. 0. https://doi. org/10.1080/15533174.2016.1228670 (2016)

18. Ghaedi, M. et al. Kinetics, thermodynamics and equilibrium evaluation of direct yellow 12 removal by adsorption onto silver nanoparticles loaded activated carbon. Chem. Eng. J. 187, 133-141 (2012).

19. Nguyen, L. H., Minh, T., Nguyen, P., Van, H. T. \& Vu, X. H. Treatment of hexavalent chromium contaminated wastewater using activated carbon derived from coconut shell loaded by silver nanoparticles: batch experiment. Wat. Air Soil Pollut. 230, 68-81 (2019).

20. Hoang, L. P. et al. Removal of $\mathrm{Cr}(\mathrm{vi})$ from aqueous solution using magnetic modified biochar derived from raw corncob. New J. Chem. 43, 18663-18672 (2019).

21. Zhao, B., Zhang, J., Yan, W., Kang, X. \& Cheng, C. Removal of cadmium from aqueous solution using waste shells of golden apple snail. Desalin. Water Treat. ISSN 3994, 1-17 (2016).

22. Ramakrishnaiah, C. R. \& Vismitha. Removal of phosphate from wastewater using low-cost adsorbents. Int. J. Eng. Invent. 1, 44-50 (2012).

23. Said, A. E. A. A., Abd El-Wahab, M. M. M. \& Abd El-Aal, M. Catalytic dehydration of methanol to dimethyl ether over nanosized WO3/Al2O3 system under inert and oxidative atmosphere. Monatsh. Chem. 147, 1507-1516 (2016).

24. Manyangadze, M. et al. Enhancing adsorption capacity of nano-adsorbents via surface modification: A review. South African J. Chem. Eng. 31, 25-32 (2020).

25. Hashemian, S. \& Reza Shahedi, M. Novel Ag/Kaolin Nanocomposite as Adsorbent for Removal of Acid Cyanine 5R from Aqueous Solution. J. Chem. 2013, 285671 (2013).

26. AbdEl-Salam, A. H., Ewais, H. A. \& Basaleh, A. S. Silver nanoparticles immobilised on the activated carbon as efficient adsorbent for removal of crystal violet dye from aqueous solutions. A kinetic study. J. Mol. Liq. 248, 833-841 (2017).

27. Altintig, E., Arabaci, G. \& Altundag, H. Preparation and characterization of the antibacterial efficiency of silver loaded activated carbon from corncobs. Surfa. Coat. Technol. 304, 63-67 (2016).

28. Inal, I. I. G., Holmes, S. M., Banford, A. \& Aktas, Z. The performance of supercapacitor electrodes developed from chemically activated carbon produced from waste tea. Appl. Surf. Sci. 357, 696-703 (2015).

29. Malhotra, M., Suresh, S. \& Garg, A. Tea waste derived activated carbon for the adsorption of sodium diclofenac from wastewater: adsorbent characteristics, adsorption isotherms, kinetics, and thermodynamics. Environ. Sci. Pollut. Res. 25, 32210-32220 (2018).

30. Foo, K. Y. \& Hameed, B. H. Utilization of biodiesel waste as a renewable resource for activated carbon: Application to environmental problems. Renew. Sustain. Energy Rev. 13, 2495-2504 (2009).

31. Ahmaruzzaman, M. \& Laxmi Gayatri, S. Activated Tea Waste as a Potential Low-Cost Adsorbent for the Removal of p-Nitrophenol from Wastewater. J. Chem. Eng. Data 55, 4614-4623 (2010).

32. Qiu, B. \& Duan, F. Synthesis of industrial solid wastes/biochar composites and their use for adsorption of phosphate: From surface properties to sorption mechanism. Colloids Surfaces A Physicochem. Eng. Asp. 571, 86-93 (2019).

33. Fang, C., Zhang, T., Li, P., Jiang, R. F. \& Wang, Y. C. Application of magnesium modified corn biochar for phosphorus removal and recovery from swine wastewater. International Journal of Environmental Research and Public Health 11, 9217-9237 (2014).

34. Huang, W. et al. Effective phosphate adsorption by $\mathrm{Zr} / \mathrm{Al}$-pillared montmorillonite: Insight into equilibrium, kinetics and thermodynamics. Appl. Clay Sci. 104, 252-260 (2015).

35. Chen, J. et al. Efficient removal of phosphate by facile prepared magnetic diatomite and illite clay from aqueous solution. Chem. Eng. J. 287, 162-172 (2016).

36. Akram, M., Bhatti, H. N., Iqbal, M., Noreen, S. \& Sadaf, S. Biocomposite efficiency for Cr(VI) adsorption: Kinetic, equilibrium and thermodynamics studies. J. Environ. Chem. Eng. 5, 400-411 (2017). 
37. Ofomaja, A. E. \& Ho, Y. S. Equilibrium sorption of anionic dye from aqueous solution by palm kernel fibre as sorbent. Dyes Pigments 74, 60-66 (2006).

38. Shukla, A., Zhang, Y.-H., Dubey, P., Margrave, J. L. \& Shukla, S. S. The role of sawdust in the removal of unwanted materials from water. J. Hazard. Mater. 95, 137-152 (2002).

39. Gong, R., Ding, Y., Liu, H., Chen, Q. \& Liu, Z. Lead biosorption and desorption by intact and pretreated spirulina maxima biomass. Chemosphere 58, 125-130 (2005).

40. Langmuir, I. The adsorption of gases on plane surfaces of glass, mica and platinum. J. Am. Chem. Soc. 40, 1361-1403 (1918).

41. Zhou, X. et al. Efficient removal of lead from aqueous solution by urea-functionalized magnetic biochar: Preparation, characterization and mechanism study. J. Taiwan Inst. Chem. Eng. 91, 457-467 (2018).

42. Shang, J. et al. Chromium removal using magnetic biochar derived from herb-residue. J. Taiwan Inst. Chem. Eng. 68, 289-294 (2016).

43. Yuan, P. et al. Montmorillonite-supported magnetite nanoparticles for the removal of hexavalent chromium [Cr(VI)] from aqueous solutions. J. Hazard. Mater. 166, 821-829 (2009).

44. Liu, Z. et al. Investigation on the adsorption of phosphorus in all fractions from sediment by modified maifanite. Sci. Rep. 8, 1-13 (2018).

45. Liu, Z. et al. Adsorption performance of modified bentonite granular (MBG) on sediment phosphorus in all fractions in the West Lake, Hangzhou, China. Ecol. Eng. 106, 124-131 (2017).

46. Vakili, M. et al. Regeneration of Chitosan-Based Adsorbents for Eliminating Dyes from Aqueous Solutions. Sep. Purif. Rev. 48, 1-13 (2019).

\section{Author contributions}

Van Tuyen Trinh, N.X. Ca and Huu Tap Van conceived and planned the experiments. L.T. Ha and Xuan Hoa Vu carried out experiments with support from Le Phuong Hoang. Thi Minh Phuong Nguyen, Thi Nu Nguyen and Le Phuong Hoang contributed to analysis samples before and after experimental processes. Tien Vinh Nguyen and Thi Minh Phuong Nguyen contributed to the interpretation of the results with support from Van Tuyen Trinh, N.V. Quang. Van Tuyen Trinh, T.T. Pham and N.X. Ca wrote the manuscript with support from Thi Minh Phuong Nguyen, L.T. Ha and N.V. Quang. All authors provided critical feedback and helped shape the research, analysis and manuscript.

\section{Competing interests}

The authors declare no competing interests.

\section{Additional information}

Correspondence and requests for materials should be addressed to X.C.N.

Reprints and permissions information is available at www.nature.com/reprints.

Publisher's note Springer Nature remains neutral with regard to jurisdictional claims in published maps and institutional affiliations.

(c) (i) Open Access This article is licensed under a Creative Commons Attribution 4.0 International License, which permits use, sharing, adaptation, distribution and reproduction in any medium or format, as long as you give appropriate credit to the original author(s) and the source, provide a link to the Creative Commons license, and indicate if changes were made. The images or other third party material in this article are included in the article's Creative Commons license, unless indicated otherwise in a credit line to the material. If material is not included in the article's Creative Commons license and your intended use is not permitted by statutory regulation or exceeds the permitted use, you will need to obtain permission directly from the copyright holder. To view a copy of this license, visit http://creativecommons.org/licenses/by/4.0/.

(c) The Author(s) 2020 